\title{
CCN activation and cloud processing in sectional aerosol models with low size resolution
}

\author{
H. Korhonen ${ }^{1}$, V.-M. Kerminen ${ }^{1}$, K. E. J. Lehtinen ${ }^{2}$, and M. Kulmala ${ }^{3}$ \\ ${ }^{1}$ Climate and Global Change, Finnish Meteorological Insitute, P.O. Box 503, FI-00101 Helsinki, Finland \\ ${ }^{2}$ University of Kuopio and Finnish Meteorological Institute, Department of Applied Physics, P.O. Box 1627, FI-70211 \\ Kuopio, Finland \\ ${ }^{3}$ Department of Physical Sciences, University of Helsinki, P.O.Box 64, FI-00014 Helsinki, Finland
}

Received: 25 May 2005 - Published in Atmos. Chem. Phys. Discuss.: 14 July 2005

Revised: 22 September 2005 - Accepted: 22 September 2005 - Published: 27 September 2005

\begin{abstract}
We investigate the influence of low size resolution, typical to sectional aerosol models in large scale applications, on cloud droplet activation and cloud processing of aerosol particles. A simplified cloud model with five approaches to determine the fraction of activated particles is compared with a detailed reference model under different atmospheric conditions. In general, activation approaches which assume a distribution profile within the critical model size sections predict the cloud droplet concentration most accurately under clean and moderately polluted conditions. In such cases, the deviation from the reference simulations is below $15 \%$ except for very low updraft velocities. In highly polluted cases, the concentration of cloud droplets is significantly overestimated due to the inability of the simplified model to account for the kinetic limitations of the droplet growth. Of the profiles examined, taking into account the local shape of the particle size distribution is the most accurate although in most cases the shape of the profile has little relevance. While the low resolution cloud model cannot reproduce the details of the out-of-the-cloud aerosol size distribution, it captures well the amount of sulphate produced in aqueous-phase reactions as well as the distribution of the sulphate between the cloud droplets. Overall, the simplified cloud model with low size resolution performs well for clean and moderately polluted regions that cover most of the Earth's surface and is therefore suitable for large scale models. It can, however, show uncertainties in areas with strong pollution from anthropogenic sources.
\end{abstract}

Correspondence to: $\mathrm{H}$. Korhonen

(hannele.korhonen@fmi.fi)

\section{Introduction}

Clouds affect the climate system of the Earth in many important ways. They are a major component in the hydrological cycle and therefore partly control the atmospheric concentration of the most important greenhouse gas, water (Ramanathan et al., 2001). Clouds and precipitation are also very important for atmospheric budgets of many reactive and climatically relevant trace gases. In addition, clouds reduce the amount of sunlight that reaches the Earth's surface, thus cooling the climate, while at the same time they absorb outgoing long-wave radiation resulting in a positive climate forcing. They also modify the size distribution and composition of atmospheric aerosol particles e.g. through chemical reactions taking place in cloud water. Furthermore, precipitating clouds are an effective removal mechanism of atmospheric particles (Andronache, 2004).

Aerosol particles, in their part, act as cloud condensation nuclei $(\mathrm{CCN})$ and can thus greatly influence the climatic properties of the clouds, such as albedo and lifetime. However, the global climate forcing resulting from aerosolcloud interactions, also called the indirect aerosol effect, remains poorly quantified (Lohmann and Feichter, 2005; Rotstayn and Liu, 2005; Sekiguchi et al., 2003). Some of the uncertainty surrounding the magnitude of the indirect effect rises from inadequate understanding of the complex relationship between aerosol and droplet concentrations. However, also the great computational expense associated with detailed simulations of relevant phenomena prevents reliable assessments of the forcing with regional and global atmospheric models.

One of the major difficulties in large scale models is that important subgrid processes need to be neglected or parameterized. Furthermore, most large scale models cannot afford to solve the physical and chemical processes related to 


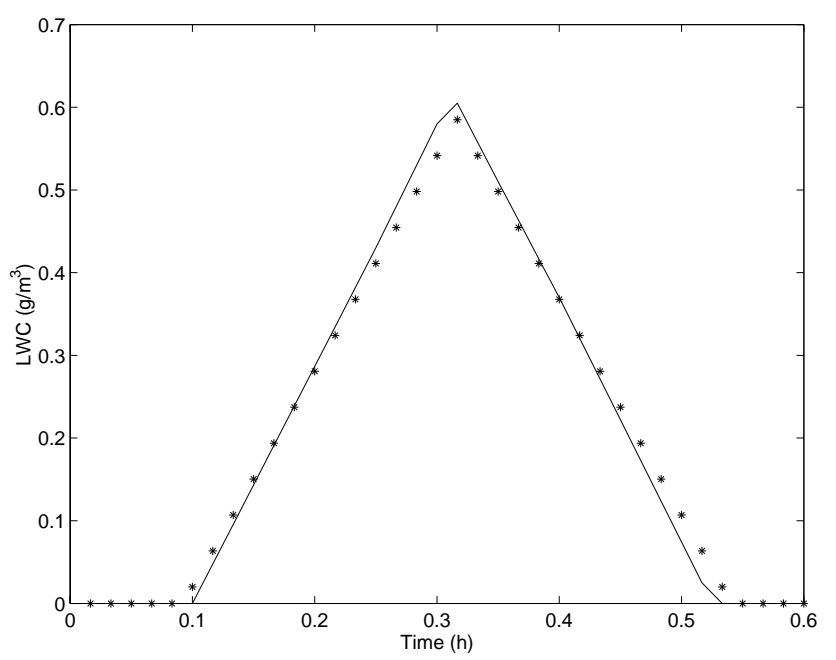

Fig. 1. Liquid water content profile inside the cloud as predicted by the approximate scheme (stars) and by detailed reference cloud model for constant updraft velocity and downdraft with the same speed (solid line).

clouds from the first principles but have to resort to simplified parameterizations. One example of such simplifications is that the models do not typically solve the profile of the cloud supersaturation, S, resulting from cooling of the rising air parcel on one hand and from condensation loss of water onto activated droplets on the other, from first principles. Instead, it is customary to diagnose the number of activated particles from the maximum supersaturation, $S_{\max }$, reached during the cloud cycle, i.e. to assume that all particles whose critical supersaturation, $S_{\text {crit }}$, is lower than $S_{\max }$ will activate. For this purpose, several parameterizations have been developed to link the aerosol distribution to the value of maximum supersaturation reached inside the cloud (e.g. Nenes and Seinfeld, 2003; Abdul-Razzak and Ghan, 2002; Abdul-Razzak et al, 1998).

Another important source of uncertainty in large scale simulations of aerosol-cloud interactions stems from the simplified representation of the aerosol size distribution. In sectional aerosol modules for 3D models, the number of particle size sections is typically limited to below or around 20 (Spracklen et al., 2005; Rodriguez and Dabdub, 2004; Zhang et al., 2004; Bessagnet et al., 2004). Such a poor size resolution can capture only the general features of the particle distribution; consequently e.g. the concentration of cloud droplets or the mass and surface area of cloud processed aerosol can differ notably from a detailed solution (Zhang et al., 2002).

In this study, we will further investigate the effect that a low sectional size resolution in models has on CCN activation and cloud processing of aerosol particles. In particular, we introduce a simplified cloud model and compare five ways to determine the fraction of particles that activate to cloud droplets under different atmospheric conditions. These five activation schemes are evaluated against a detailed adiabatic cloud model based on the prediction of cloud droplet concentration and aerosol distribution after one and several cloud cycles.

\section{Model description}

An existing sectional multicomponent aerosol model UHMA (Korhonen et al., 2004) was extended with a cloud scheme that resembles in complexity those used in large scale models. This scheme does not solve the growth of the cloud droplets from first principles but instead it diagnoses the number and size of activated droplets from three prescribed input parameters: maximum supersaturation reached inside the cloud $\left(S_{\max }\right)$, time the air parcel spends inside the cloud $\left(\Delta t_{\text {cloud }}\right)$ and the average liquid water content of the cloud (LWC). The three input parameters were used to diagnose the cloud properties in the following way: The number of activated droplets was determined from $S_{\max }$ individually for each aerosol size section. Treating each section separately is necessary since the chemical composition of the particles can differ between the sections. Instead of assuming that the cloud liquid water content is a constant function of height, we assumed that the profile increases linearly from the bottom to the top of the cloud. An example of the resulting profile, which can be calculated from the average LWC and the time inside the cloud, $\Delta t_{\text {cloud }}$, is shown in Fig. 1 against a reference model simulation with a constant updraft. It can be seen that the simple profile corresponds to a good accuracy to cases when the updraft velocity is constant. Furthermore, several observations support our choice of a linear increase of cloud liquid water content as a function of height (e.g. Brenguir et al., 2000). With a further assumption that all the activated particles grow to same droplet size, we can use the liquid water content profile to calculate the size of the cloud droplets as a function of height from the cloud base as well as the amount of sulphate produced in aqueous phase reactions during the cloud cycle.

The three prescribed parameters, namely $S_{\max }$, LWC and $\Delta t_{\text {cloud }}$, were in this study taken from reference model simulations in order to facilitate the comparison between the simplified model and a reference dynamic cloud model described below. In large scale models, the liquid water content, and the time the activated and interstitial particles are influenced by the cloud are typically available in one form or another but the maximum supersaturation needs to be calculated from other variables. Several parameterizations (e.g. Nenes and Seinfeld, 2003; Abdul-Razzak and Ghan, 2002) have been developed to link $S_{\max }$ to the particle distribution, cloud updraft velocity and other relevant model quantities. Any of these parameterizations could be easily incorporated into our simplified cloud model. 
Approach 1

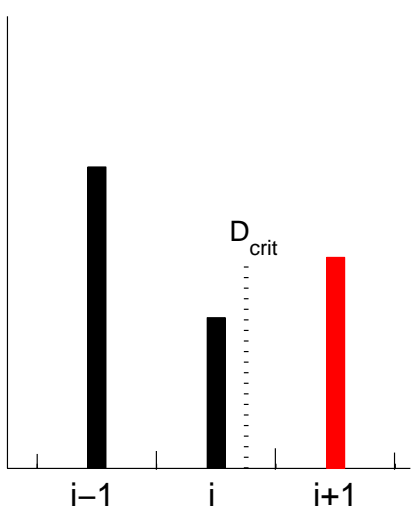

Approach 3

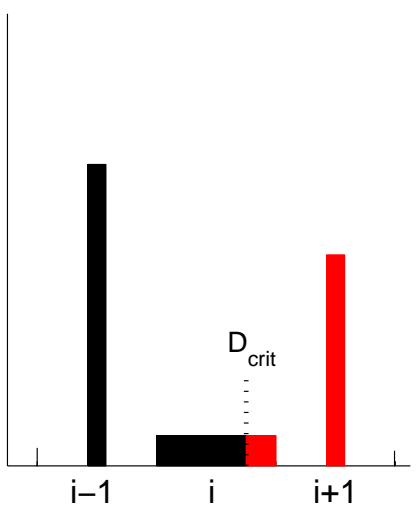

Approach 2

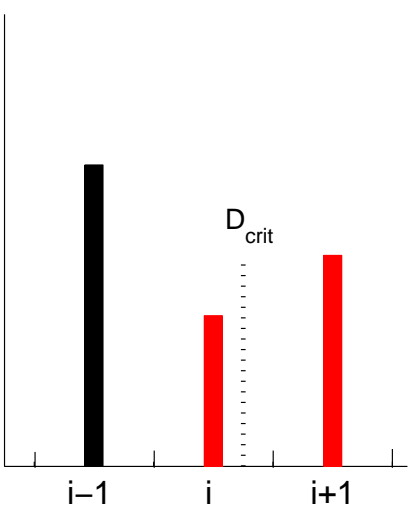

Approach 4

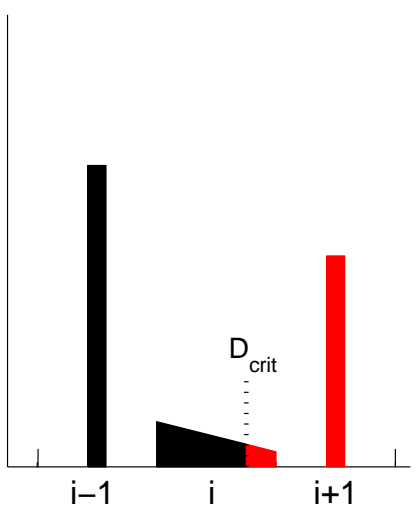

Approach 5

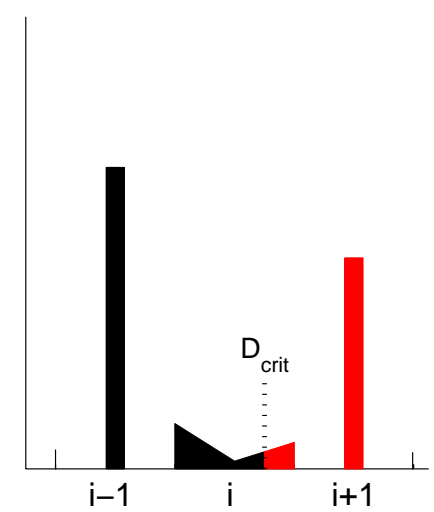

Fig. 2. Schematic figure of CCN activation approaches used. For each approach, the sections and fractions of sections in red are activated while the sections and fractions of sections in black remain as interstitial. The dotted vertical line corresponds to the critical activation diameter. For approaches 3, 4 and 5, the slopes and the height of the particle distribution profile in the critical section are exaggerated.

Aerosol model UHMA offers several ways to describe the particle size distribution. The simulations presented here were conducted with three sectional descriptions: with fixed sections, with full-moving sections, and with moving-center approach (Jacobson, 1997). In all these descriptions the size sections are spaced according to particle dry size, and thus particles do not move between sections due to water condensation. All the particles in a section are internally mixed and have the same size which is called the characteristic size of the section. For fixed and moving center descriptions, the lower and upper boundaries of the sections are fixed in location and spaced logarithmically around the initial characteristic size. For full-moving description the boundaries are determined separately for each cloud cycle from spacing of the characteristic sizes at that moment.

In most of the simulations the model was run in dry particle diameter range $10 \mathrm{~nm}-1.5 \mu \mathrm{m}$ with 10 size sections, a resolution that roughly corresponds to or exceeds that of most current global or regional scale models. With such sparse spacing, special attention must be paid to the critical sec- tion(s), i.e. size section(s) into which a minimum activation diameter falls. In this study, we tested five approaches to determine the fraction of particles activated in a critical section (Fig. 2):

1. all particles in section activate if $S_{\max }$ larger than $S_{\text {crit }}$ of the characteristic size of the section

2. all particles in section activate if $S_{\max }$ larger than $S_{\text {crit }}$ of the upper boundary size of the section

3. uniform distribution profile within section that conserves particle number; particles whose $S_{\text {crit }}$ smaller than $S_{\max }$ activate

4. linear distribution profile within section that conserves particle number and volume; particles whose $S_{\text {crit }}$ smaller than $S_{\max }$ activate

5. continuous profile that consists of two linear profiles whose slopes take into account the particle concentration in neighbouring sections, and which conserves 
particle number; particles whose $S_{\text {crit }}$ smaller than $S_{\max }$ activate.

As shown in Fig. 2, approaches 3, 4 and 5 typically activate only a part of the particles in a critical section. In such sections, the particles are split into activated and interstitial subgroups in a mass-conservative way and the two subgroups are treated separately for the duration of the cloud cycle.

In summary, the simplified cloud model described above represents the cloud with three prescribed parameters and the aerosol particle size distribution with only 10 size sections. The results from the this model were compared against a dynamic adiabatic cloud model (used as a reference model in this study) which solves explicitly for the saturation and liquid water content profiles inside the cloud, as well as for the condensation of water onto the cloud droplets. This cloud scheme was adapted from Kerminen (2001) and run interactively with the same aerosol dynamics as the simplified model.

One should also note that many large scale models apply modal (typically log-normal) rather than sectional representation of the particle size distribution. Due to the different philosophy behind these two representations, the activation approaches and sulphate formation in the aqueous phase used in this study cannot be generalized to modal models in a straightforward way. However, several activation concepts have been suggested for modal models in earlier work, ranging from detailed parameterizations (e.g. Fountoukis and Nenes, 2005; Abdul-Razzak et al., 1998) to simple treatment of cloud processing only for water-soluble accumulation and coarse mode particles (Stier et al., 2005).

\section{Simulation design}

We evaluated the five activation approaches in the simplified model against the reference model with 500 size sections. The three prescribed cloud properties needed for the simplified model, namely $S_{\max }, \Delta t_{\text {cloud }}$ and LWC, were taken from the reference simulations for each cloud cycle. Although in the simulations presented in this study we run the models only for condensation, activation of CCNs and aqueousphase sulphate formation, the simulations can be easily extended to other relevant aerosol processes.

Ideally, the simplified model should reproduce the reference results in three respects: Firstly, the number of activated particles should be resolved accurately. Secondly, the formation and distribution of sulphate in aqueous phase reactions should be described correctly. Thirdly, the simplified model with low resolution in size distribution description should reproduce the aerosol particle distribution after several successive cloud cycles with different saturation conditions.

We performed simulations of single and several successive cloud cycles with typical marine, rural, and urban aerosol distributions taken from Jaenicke (1993) and presented in Table 1. For simplicity, the particles were initially assumed to consist of ammonium sulphate and slightly water-soluble organics in a ratio of 1:1. During the simulations the particle composition changed due to condensation of sulphuric acid and due to aqueous-phase oxidation of $\mathrm{SO}_{2}$ with $\mathrm{H}_{2} \mathrm{O}_{2}$. Only this oxidation reaction was considered as it is clearly the dominant one in acidic cloud droplets which would form from the assumed dry aerosol. Although our description of aerosol distribution and interaction with the gas phase is highly idealized, using different initial composition or more detailed condensation and sulphate formation mechanisms would not change the main conclusions of the study. It could, however, affect the magnitude of the results at least to some extent and thus the results should be considered relative to the reference model.

In all the simulations presented below, the initial concentration of $\mathrm{H}_{2} \mathrm{O}_{2}$ was set to $500 \mathrm{ppt}$ (Seinfeld and Pandis, 1998). On the other hand, the initial concentration of $\mathrm{SO}_{2}$ was adjusted to a typical pollution level of the simulated environment, i.e. $70 \mathrm{ppt}$ for marine conditions, $500 \mathrm{ppt}$ for rural conditions, and $2500 \mathrm{ppt}$ for urban conditions (Seinfeld and Pandis, 1998). The concentration of OH, which was responsible for gas-phase oxidation of $\mathrm{SO}_{2}$ to sulphuric acid, followed a semisinusoidal pattern starting at $2 \times 10^{6} \mathrm{~cm}^{-3}$ and peaking at $5 \times 10^{6}$ molecules $/ \mathrm{cm}^{3}$ after $9 \mathrm{~h}$ (Seinfeld and Pandis, 1998). The maximum height that the ascending air parcel reached and the updraft velocity were varied between the cloud cycles.

All the model runs begun close to the ground with initial relative humidity and temperature of $63.5 \%$ and $293 \mathrm{~K}$. Particle activation was assumed to start in the simplified model once the relatively humidity rose above $99.9 \%$, and the cloud was assumed to evaporate once the prescribed time inside the cloud had passed. Both models simulated also the descent of the air parcel from the cloud top and let the relevant physical and chemical processes modify the aerosol distribution in the downdraft (inside the cloud as well as below the cloud base). The simulation of each cloud cycle ended when the air parcel reached its starting height close to the ground. In the simulations of successive cloud cycles the aerosol distribution from the previous cycle was used as input for the next cycle.

\section{Results and discussion}

\subsection{Single cloud cycle}

Figure 3 compares the predictions of the five activation approaches in terms of cloud droplet concentration for a single cloud cycle. The results have been normalized by the droplet concentration obtained from the reference model. The results presented are for moving center description of the particle size distribution but the other two descriptions tested, i.e. fixed and full-moving sections, give essentially the same results. 
Table 1. Initial particle size distributions used in the simulations. Values have been taken from Jaenicke (1993).

\begin{tabular}{llllllllll}
\hline & \multicolumn{3}{c}{ Marine } & & Rural & & \multicolumn{3}{c}{ Urban } \\
& $\mathrm{D}(\mu \mathrm{m})$ & $\mathrm{N}\left(\mathrm{cm}^{-3}\right)$ & $\log \sigma$ & $\mathrm{D}(\mu \mathrm{m})$ & $\mathrm{N}\left(\mathrm{cm}^{-3}\right)$ & $\log \sigma$ & $\mathrm{D}(\mu \mathrm{m})$ & $\mathrm{N}\left(\mathrm{cm}^{-3}\right)$ & $\log \sigma$ \\
\hline Mode I & 0.008 & 133 & 0.657 & 0.015 & 6650 & 0.225 & 0.013 & $9.93 \mathrm{E}+04$ & 0.245 \\
Mode II & 0.266 & 66.6 & 0.210 & 0.054 & 147 & 0.557 & 0.014 & $1.11 \mathrm{E}+04$ & 0.666 \\
Mode III & 0.580 & 3.1 & 0.396 & 0.084 & 1990 & 0.266 & 0.050 & $3.64 \mathrm{E}+04$ & 0.337 \\
\hline
\end{tabular}
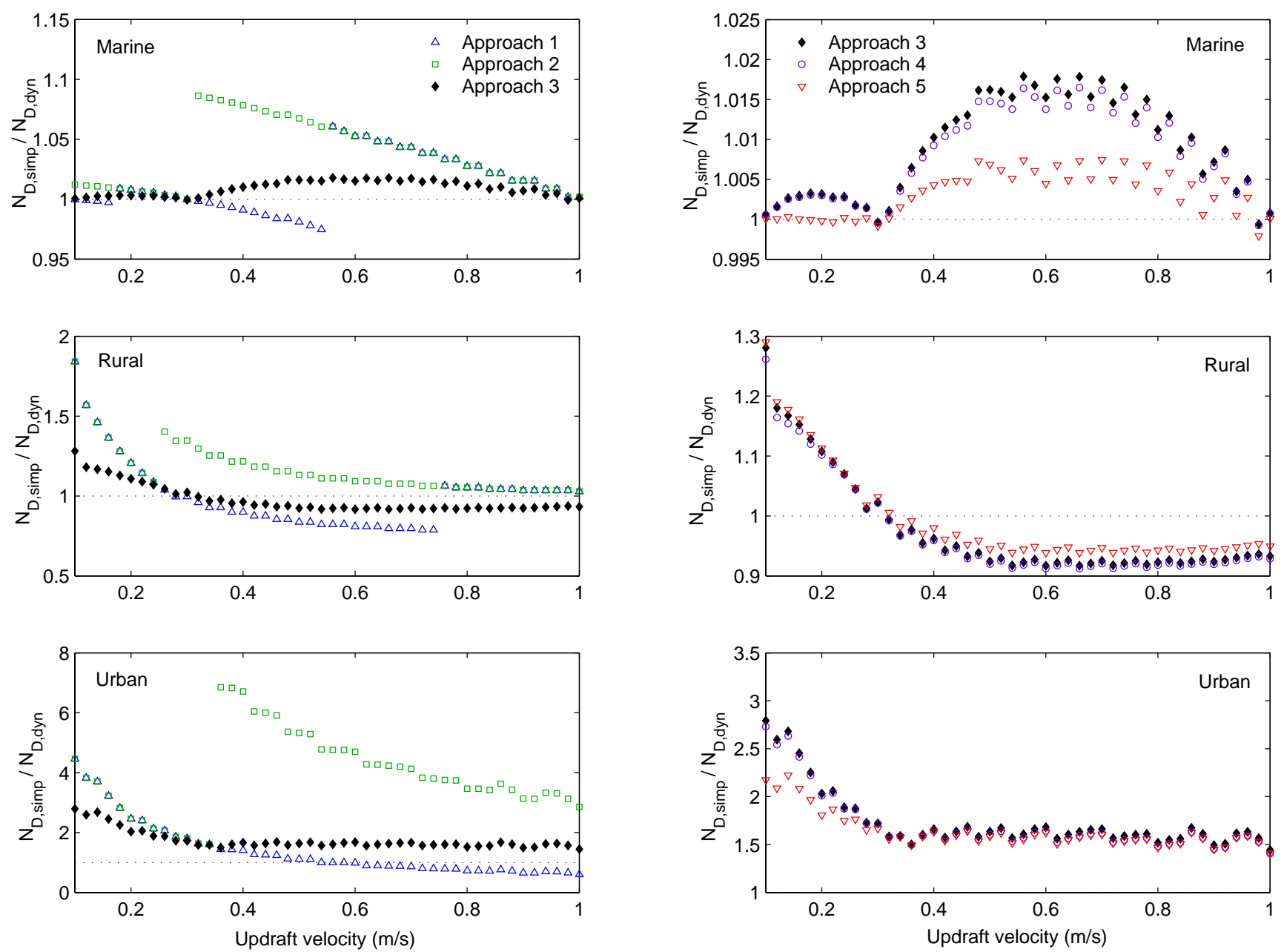

Fig. 3. Predictions of cloud droplet concentrations from 5 activation schemes normalized with results from the reference cloud model. All simulations with the simplified model have been made independently of each other with 10 size sections in size range $10 \mathrm{~nm}-1.5 \mu \mathrm{m}$ and with moving center description. Note that the scale of the y-axis is different in each subplot.

Firstly, it is evident that the performance of the simplest approaches which assume that either all or none of the particles in each section activate, i.e. approaches 1 and 2, varies greatly over the simulated updraft range (Fig. 3, left panel). These two approaches predict exactly the same droplet concentration at times when the maximum supersaturation reached in the cloud falls in the critical section between the critical supersaturation of the lower boundary size and that of the characteristic particle size. For a large majority of the simulated cloud cycles, however, approach 2 generates the greatest deviation from the reference results. This is because it activates all the particles in a section as soon as $S_{\max }$ exceeds the critical supersaturation of the upper boundary size. In practice this means that approach 2 never underestimates the number of cloud droplets. 
Table 2. Percent error in cloud droplet concentrations from the reference model values in a simulation of five successive cloud cycles. Results for the simplified model have been obtained with 10 size sections in size range $10 \mathrm{~nm}-1.5 \mu \mathrm{m}$ and with moving center description.

\begin{tabular}{rrrrrrr}
\hline & & \multicolumn{5}{c}{ Approach } \\
\hline \multirow{4}{*}{ Marine } & & 1 & 2 & 3 & 4 & 5 \\
\hline & cycle 1 & 0.8 & 0.8 & 0.4 & 0.4 & $<0.1$ \\
& cycle 2 & -2.4 & 6.2 & 1.3 & 1.3 & 0.2 \\
& cycle 3 & 1.1 & 1.1 & 0.4 & 0.4 & -0.6 \\
& cycle 4 & -2.1 & 26.5 & 3.6 & 3.8 & 2.4 \\
& cycle 5 & -2.1 & 26.5 & 3.6 & 3.8 & 2.4 \\
\hline \multirow{4}{*}{ Rural } & cycle 1 & 18.4 & 18.4 & 8.3 & 7.7 & 8.8 \\
& cycle 2 & -14.5 & 15.5 & -7.4 & -7.5 & -5.7 \\
& cycle 3 & -20.6 & 7.2 & -6.5 & -6.7 & -4.3 \\
& cycle 4 & 4.0 & 4.0 & -4.3 & -4.4 & -2.4 \\
& cycle 5 & 5.8 & 5.8 & -12.6 & -12.7 & -10.4 \\
\hline \multirow{4}{*}{ Urban } & cycle 1 & 151.9 & 151.9 & 107.2 & 104.7 & 83.7 \\
& cycle 2 & 48.1 & 48.1 & 48.1 & 48.1 & 48.1 \\
& cycle 3 & 13.6 & 441.4 & 43.0 & 42.1 & 40.8 \\
& cycle 4 & 1.2 & 382.1 & 57.3 & 55.8 & 53.9 \\
& cycle 5 & 45.9 & 45.9 & 25.9 & 39.5 & 10.5 \\
\hline
\end{tabular}

On the other hand, the results for approaches 3, 4 and 5 all of which assume a continuous distribution profile within the critical size section - are very similar (Fig. 3, right panel). Only approach 5 , which calculates the profile by taking into account the particle concentration in neighbouring sections, systematically predicts slightly more accurate results than its counterparts. However, even these three approaches perform poorly in some simulations, most notably under urban conditions and with low updraft velocities. Under these conditions, kinetic limitations of droplet formation are often significant, as discussed in detail by Nenes et al. (2001) and Kulmala et al. (1993). For some particles, situations may arise when the particles activate at first as the saturation of water in the air parcel rises above their critical supersaturation. If condensation onto the forming cloud droplets becomes very fast, however, the supersaturation of the parcel may drop below the equilibrium saturation level of these particles and they deactivate to become interstitial particles. This effect cannot be described in simplified cloud schemes, such as ours, which assume instantaneous response of particles to supersaturation changes and calculate the number of activated droplets directly from the maximum saturation reached during the cloud cycle. Therefore, simplified schemes regardless of their activation approach tend to overestimate the number of cloud droplets under conditions when the supersaturation increases slowly compared to the loss of water by condensation.

\subsection{Several successive cloud cycles}

A second set of simulations compared the activation approaches in terms of cloud droplet concentration, out-ofcloud size distribution and production of aqueous-phase sulphate over five successive cloud cycles. The boundary layer depth and updraft velocity were varied between the five cloud cycles and set to $1000,1200,1200,1500$ and $1000 \mathrm{~m}$, and to $0.2,0.5,0.8,1.0$ and $0.4 \mathrm{~m} / \mathrm{s}$, respectively. The changing conditions reflect qualitatively the cycling of the aerosol particles in real cloudy atmosphere in which particles experience variant updraft and cloud thickness. Moreover, the variation between the cloud cycles puts the cloud activation and cloud processing schemes to a more stringent test than several cloud cycles with same maximum supersaturations would. Again, the three prescribed cloud properties for the simplified model were taken from the reference simulations. The results presented below are for moving center description of the size distribution unless stated otherwise.

Table 2 summarizes the results from the simplified model regarding the predicted concentration of cloud droplets. The values given are percent differences from the reference model results. In general, this set of simulations confirms the conclusions presented for a single cloud cycle: The number of activated particles is most accurately reproduced by assuming a particle profile inside the size sections, approach 5 yielding slightly better results than the two other profiles. Overall, the deviation of these three approaches from reference model under rural and marine conditions is always less than $13 \%$, which can be considered very satisfactory for a simplified low-resolution model. For urban conditions the ostensibly good results of approach 1 during some of the cloud cycles stem from the overall poor performance of the simplified cloud model. As explained above, the neglect of kinetic limitations leads the simplified model to overestimate the number of cloud droplets. At the same time, approach 1 tends to underestimate the droplet concentration because it assumes that no activation occurs in a section unless $S_{\max }$ is larger than $S_{\text {crit }}$ for the characteristic size of that section.

The results presented in Table 2 were obtained with the moving center description. Although not shown here, the other two ways to describe the particle size distribution in the model, namely fixed and full-moving sectional methods, yield very similar results. For a combined data set of the most accurate activation approaches 3, 4 and 5, and of all the three environmental conditions, the median (mean) deviation from the reference results for fixed, full-moving, and moving center approaches are $6.1 \%(24.0 \%), 6.3 \%(24.4 \%)$, and $7.4 \%$ (20.9\%), respectively. The strength of the last two size distribution description becomes, however, evident when we double the number of size sections to 20 . Then the cloud droplet numbers from full-moving description agree best with the reference results, the median deviation being $0.8 \%$ in comparison with $3.6 \%$ for fixed description and $1.7 \%$ for moving center description. In aerosol dynamic models, however, 
the fixed and moving center methods are often preferable over the full-moving one because of their more advantageous description of particle transport, emissions and nucleation. It is also worth note that although doubling the particle size resolution improved the results significantly under marine and rural cases, the deviation from the reference simulations in fact slightly increased under urban conditions for which the kinetic limitations of droplet growth are important.

Figure 4 illustrates that the simplified model reproduces the general features of the cloud processed aerosol size distribution fairly well but cannot capture the details of the distribution due to the low resolution, as reported earlier by Zhang et al. (2002). For example, the approaches which assume a distribution profile within the critical diameter (here represented by approach 5) do not show Hoppel minimum (Hoppel et al., 1994) at all since they activate only some of the particles in the critical sections. At the same time the simpler approaches 1 and 2 predict a much too wide minimum after several cloud cycles.

All the activation approaches predict the amount of sulphate formed in the cloud droplets, i.e. the total dry mass change during each cloud cycle, very well (Fig. 5). This is not surprising since the oxidation rate of $\mathrm{SO}_{2}$ is highly dependent on the liquid water content of the cloud whose average value is a prescribed parameter in our simplified model and whose profile is well captured for constant updraft velocities. On the other hand, distribution of the formed sulphate onto the droplets, represented in Fig. 5 through the change in total dry surface area during each cloud cycle, shows some variation between the activation approaches. Especially approach 2, which often overestimates the number of activated particles (Fig. 3), tends to overestimate the formed surface area. Approaches 1 and 5 both reproduce the results from the reference simulation relatively well. On average, however, approach 1 performs slightly more accurately in this respect under the simulated conditions.

The results shown in Figs. 4 and 5 are for moving center description. The other two descriptions predict nearly identical dry mass increase as the moving center method (no figure). The fixed description, however, clearly overestimates the dry surface area increase during the cloud cycles. This is due to numerical diffusion which originates from splitting the droplet core material between fixed size sections when sulphate formed in the cloud is added to the droplets (Korhonen et al., 2003).

Regarding the mass of sulphate produced in the cloud, it is important to note that the good agreement with the reference model can be partly due to the assumption made about the aerosol dry composition. In the real atmosphere, the composition of the effective $\mathrm{CCN}$ often is a function of size (Moore et al., 2004). In the simulations presented above, the dry particles consisted only of ammonium sulphate and slightly soluble organic matter. The cloud droplets forming on such particles are acidic and thus the dominant oxidation path of $\mathrm{SO}_{2}$ in the droplets is with $\mathrm{H}_{2} \mathrm{O}_{2}$, a reaction that is only very
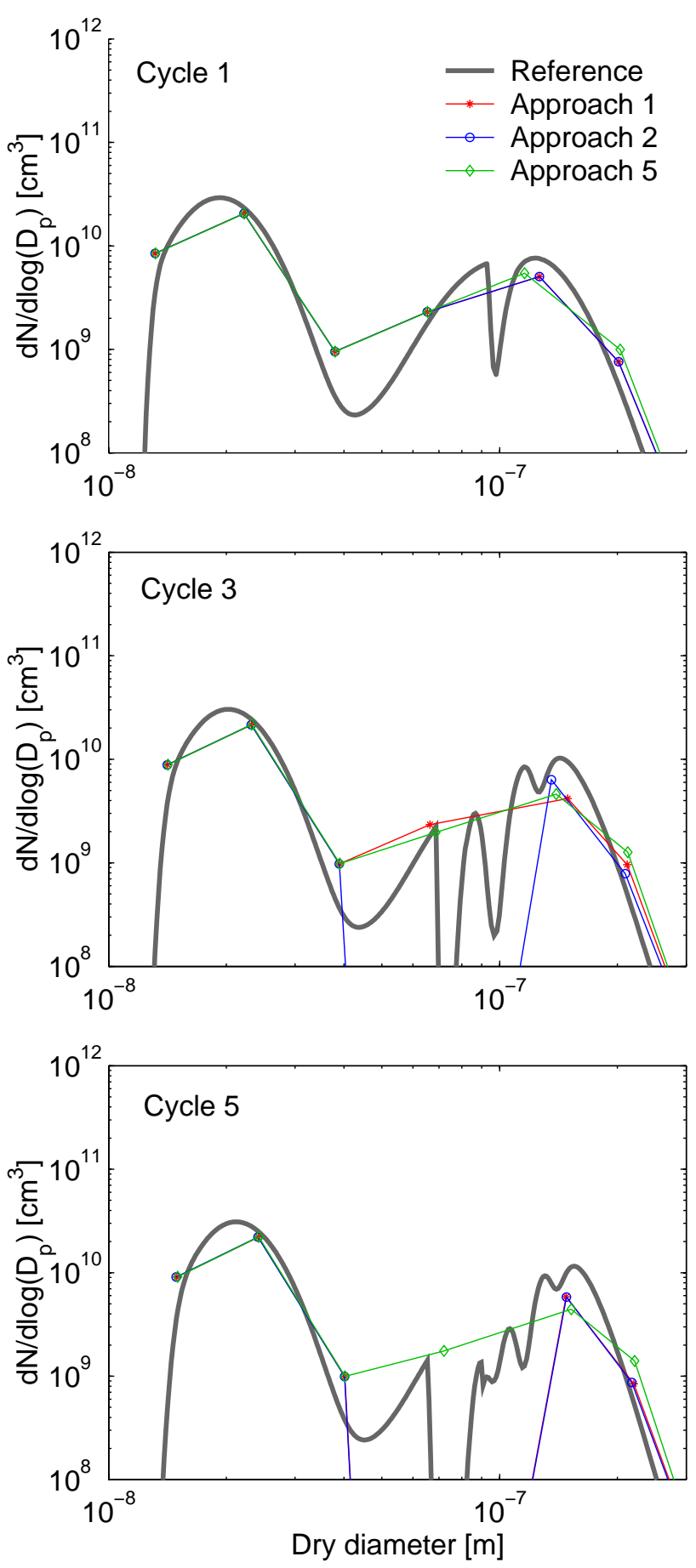

Fig. 4. Dry aerosol size distribution under rural conditions after 1 , 3 and 5 cloud cycles. Activation approaches 3, 4 and 5 give almost identical results and thus only results for approach 5 are shown. All simulations with the simplified model have been made with 10 size sections in size range $10 \mathrm{~nm}-1.5 \mu \mathrm{m}$ and with moving center description.

weakly dependent on the $\mathrm{pH}$ of individual cloud droplets. In less acidic clouds, however, oxidation reactions that depend 

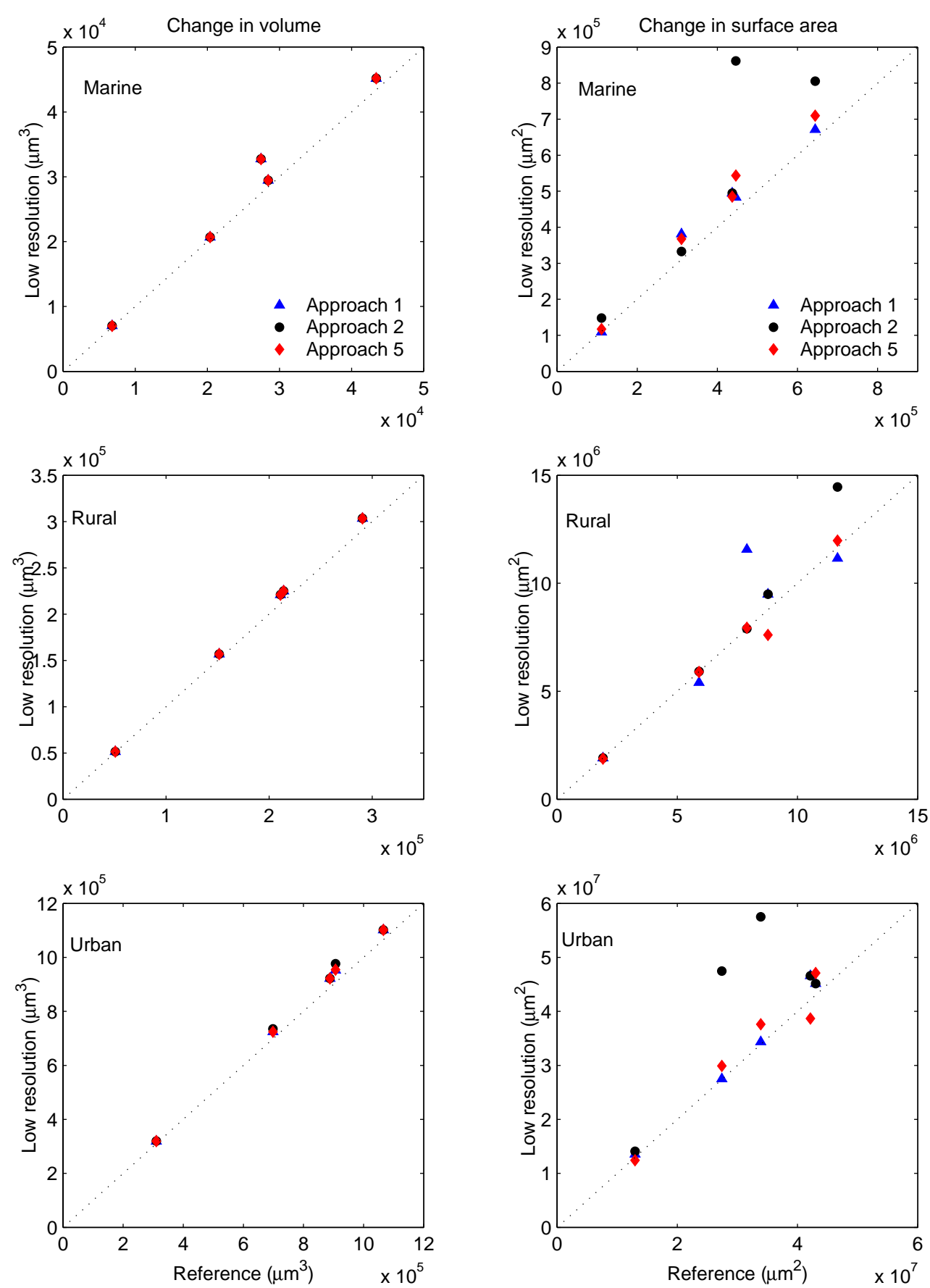

Fig. 5. Change of total dry mass and total dry surface area during individual cloud cycles. Activation approaches 3,4 and 5 give almost identical results and thus only results for approach 5 are shown. All simulations with the simplified model have been made with 10 size sections in size range $10 \mathrm{~nm}-1.5 \mu \mathrm{m}$ and with moving center description.

strongly on the $\mathrm{pH}$, such as the reaction of $\mathrm{SO}_{2}$ with $\mathrm{O}_{3}$, become important. It is then advantageous to use size-resolving cloud models which calculate the size and $\mathrm{pH}$ distribution of cloud droplets dynamically taking into account the dilution factors and initial dry composition of different sized particles (Kreidenweis et al., 2003; Gurciullo and Pandis, 1997).
As our simplified cloud model carries separately the dry and wet size of droplets, it could in principle be used to calculate their $\mathrm{pH}$ differences to a fair accuracy. In cases when the cloud droplet distribution would not in reality be close to monodisperse, the simplified model can, however, lead to deviations from an accurate solution. 


\section{Conclusions}

We have evaluated the impact that a low size resolution in sectional aerosol models and a simple cloud scheme have on simulated cloud droplet number and cloud processing of aerosol particles. Our simplified model used diagnoses of the properties of the cloud from only three input parameters: maximum supersaturation reached inside the cloud, time the air parcel spends in the cloud and average cloud liquid water content. Five approaches to determine the activated fraction of $\mathrm{CCN}$ were incorporated into this simplified model and compared in their ability to predict the concentration of droplets, sulphate formed in aqueous phase reactions and out-of-cloud dry particle size distribution over one or more cloud cycles.

Overall, the simplified low resolution model agreed fairly well with the reference model under marine and rural conditions. In the polluted urban case, the simplified model, which cannot resolve the kinetic effects of cloud droplet growth, was not able to predict the cloud droplet number accurately. For marine and rural conditions, the assumption of a distribution profile inside the critical size section(s) clearly improved the prediction of the cloud droplet concentration. In most cases simulated here, however, the shape of the profile was almost irrelevant as a flat profile (approach 3), a tilted linear profile (approach 4) and a profile which in a crude way takes into account the local shape of the particle distribution (approach 5) produced nearly identical results. Approach 5 still performed slightly better than its counterparts, and would be advantageous especially in situations when the aerosol size distribution shows steep local slopes in particle concentration in the CCN size range. Although the low resolution scheme cannot reproduce the small details of the cloud processed particle size distribution, it predicted the changes of total dry mass and surface area during the cloud cycles to a good accuracy. Only one of the activation approaches (approach 2) was clearly inferior to the others in this respect.

The simulations show that a simplified cloud model with a size resolution typical to large scale models can describe the $\mathrm{CCN}$ activation and cloud processing of aerosol particles fairly accurately. Only under conditions for which the kinetic limitations of the droplet growth are significant, i.e. essentially urban and other highly polluted environments, the simplified model clearly overestimates the concentration of forming cloud droplets. Since the vast majority of the Earth's surface is covered by marine, remote or rural environment, for which the tested scheme agrees well with reference simulations, a simplified low-resolution cloud model is in general suited for large scale modelling purposes. It can, however, show uncertainties in areas with strong pollution from anthropogenic sources.

Acknowledgements. This work has been supported by Academy of Finland (projects 205798 and 208208).

\section{References}

Abdul-Razzak, H., Ghan, S. J., and Rivera-Carpio, C.: A parameterization of aerosol activation, 1. Single aerosol type, J. Geophys. Res., 103, 6123-6131, 1998.

Abdul-Razzak, H. and Ghan, S. J.: A parameterization of aerosol activation, 3. Sectional representation, J. Geophys. Res., 107(D3), 4026, doi:10.1029/2001JD000483, 2002.

Andronache, C.: Precipitation removal of ultrafine aerosol particles from the atmospheric boundary layer, J. Geophys. Res., 109, D16S07, doi:10.1029/2003JD004050, 2004.

Bessagnet, B., Hodzic, A., Vautard, R., Beekman, M., Cheinet, S., Honoré, C., Liousse, C., and Rouil, L.: Aerosol modeling with CHIMERE - preliminary evaluation at the continental scale, Atmos. Environ., 38, 2803-2817, 2004.

Brenguier, J.-L., Pawlowska, H., Schuller, L., Preusker, R., Fischer, J., and Fouquart, Y.: Radiative properties of boundary layer clouds: droplet effective radius versus number concentration, J. Atmos. Sci., 57, 803-821, 2000.

Fountoukis, C. and Nenes, A.: Continued development of a cloud droplet formation parameterization for global climate models, $\mathrm{J}$. Geophys. Res., 110, D11212, doi:10.1029/2004JD005591, 2005.

Gurciullo, C. S. and Pandis, S. N.: Effect of composition variations in cloud droplet populations on aqueous-phase chemistry, J. Geophys. Res., 102, 9375-9385, 1997.

Hoppel, W. A., Frick, G. M., Fitzgerald, J., and Larson, R. E.: Marine boundary layer measurements of new particle formation and the effects non-precipitating clouds have on aerosol size distribution, J. Geophys. Res., 99, 14 443-14 459, 1994.

Jacobson, M. Z.: Development and application of a new air pollution modeling system - II. Aerosol module structure and design, Atmos. Environ., 31, 131-144, 1997.

Jaenicke, R.: Tropospheric aerosols, in: Aerosol-cloud-climate interactions, edited by: Hobbs, P. V., Academic Press, San Diego, 1-31, 1993.

Kerminen, V.-M.: Relative roles of secondary sulfate and organics in atmospheric cloud condensation nuclei production, J. Geophys. Res., 106(D15), 17 321-17333, 2001.

Korhonen, H., Lehtinen, K. E. J., Pirjola, L., Napari, I., Vehkamäki, H., Noppel, M., and Kulmala, M.: Simulation of atmospheric nucleation mode: A comparison of nucleation models and size distribution descriptions, J. Geophys. Res., 108(D15), 4471, doi:10.1029/2002JD003305, 2003.

Korhonen, H., Lehtinen, K. E. J., and Kulmala, M.: Aerosol dynamic model UHMA: Model development and validation, Atmos. Chem. Phys., 4, 757-771, 2004,

SRef-ID: 1680-7324/acp/2004-4-757.

Kreidenweis, S. M., Walcek, C. J., Feingold, G., Gong, W., Jacobson, M. Z., Kim, C.-H., Liu, X., Penner, J. E., Nenes, A., and Seinfeld, J. H.: Modification of aerosol mass and size distribution due to aqueous-phase $\mathrm{SO}_{2}$ oxidation in clouds: Comparisons of several models, J. Geophys. Res., 107(D7), 4213, doi:10.1029/2002JD002697, 2003.

Kulmala, M., Laaksonen, A., Korhonen, P., Vesala, T., and Ahonen, T.: The effect of atmospheric nitric acid vapor on cloud condensation nucleus activation, J. Geophys. Res., 98, 22 949-22 958, 1993.

Edited by: B. Kärcher 
Lohmann, U. and Feichter, J.: Global indirect aerosol effects: a review, Atmos. Chem. Phys., 5, 715-737, 2005,

SRef-ID: 1680-7324/acp/2005-5-715.

Moore, K. F., Sherman, D. E., Reilly, J. E., and Collett Jr., J. L. : Drop size-dependent chemical composition in clouds and fogs, Part I, Observations, Atmos. Environ., 38, 1389-1402, 2004.

Nenes, A. and Seinfeld, J. H.: Parameterization of cloud droplet formation in global climate models, J. Geophys. Res., 108(D14), 4415, doi:10.1029/2002JD002911, 2003.

Nenes, A., Ghan, S., Abdul-Razzak, H., Chuang, P. Y., and Seinfeld, J. H.: Kinetic limitations on cloud droplet formation and impact on cloud albedo, Tellus, 53B, 113-149, 2001.

Ramanathan, V., Crutzen, P. J., Kiehl, J. T., and Rosenfeld, D.: Aerosols, climate and the hydrological cycle, Science, 294, 2119-2124, 2001.

Rodriguez, M. A. and Dabdub, D.: IMAGES-SCAPE2: A modelling study of size- and chemically resolved aerosol thermodynamics in a global chemical transport model, J. Geophys. Res., 109, D02203, doi:10.1029/2003JD003639, 2004.

Rotstayn, L. D. and Liu, Y.: A smaller estimate of the second indirect aerosol effect, Geophys. Res. Lett., 32, L05708, doi:10.1029/2004GL021922, 2005.

Seinfeld, J. H. and Pandis, S. N.: Atmospheric chemistry and physics, John Wiley \& Sons, New York, 1998.
Sekiguchi, M., Nakajima, T., Suzuki, K., Kawamoto, K., Higurashi, A., Rosenfeld, D., Sano, I., and Mukai, S.: A study of the direct and indirect effects of aerosols using global satellite data sets of aerosol and cloud parameters, J. Geophys. Res., 108(D22), 4699, doi:10.1029/2002JD003359, 2003.

Spracklen, D. V., Pringle, K. J., Carslaw, K. S., Chipperfield, M. P., and Mann, G. W.: A global off-line model of size-resolved aerosol microphysics: I. Model development and prediction of aerosol properties, Atmos. Chem. Phys., 5, 2227-2252, 2005,

SRef-ID: 1680-7324/acp/2005-5-2227.

Stier, P., Feichter, J., Kinne, S., Kloster, S., Vignati, E., Wilson, J., Ganzeveld, L., Tegen, I., Werner, M., Balkanski, Y., Schulz, M., Boucher, O., Minikin, A., and Petzold, A.: The aerosol-climate model ECHAM5-HAM, Atmos. Chem. Phys., 5., 1125-1156, 2005.

Zhang, Y., Easter, R. C., Ghan, S. H., and Abdul-Razzak, H.: Impact of aerosol size distribution on modelling aerosol-cloud interactions, J. Geophys. Res., 107(D21), 4558 , doi:10.1029/2001JD001549, 2002.

Zhang, Y., Pun, B., Vijayaraghavan, K., Wu, S.-Y., Seigneur, C., Pandis, S. N., Jacobson, M. Z., Nenes, A., and Seinfeld, J. H.: Development and application of the Model of Aerosol Dynamics, Reaction, Ionization, and Dissolution (MADRID), J. Geophys. Res., 109, D01202, doi:10.1029/2003JD003501, 2004. 